\title{
Monitoramento do percevejo marrom Euschistus heros (Hemiptera: Pentatomidae) por feromônio sexual em lavoura de soja
}

\author{
Valvenarg Pereira da Silva(1), Mônica Josene Barbosa Pereira( ${ }^{(1)}$, Lúcia Madalena Vivann ${ }^{(2)}$, \\ Maria Carolina Blassioli-Moraes ${ }^{(3)}$, Raúl Alberto Laumann ${ }^{(3)}$ e Miguel Borges ${ }^{(3)}$

\begin{abstract}
(1) Universidade do Estado de Mato Grosso, Centro de Pesquisas, Estudos e Desenvolvimento Agroambientais, Laboratório de Entomologia, Campus de Tangará da Serra, Rodovia MT 358, Km 7, Jardim Aeroporto, CEP 78300-000 Tangará da Serra, MT, Brasil. E-mail: silvabiologo@hotmail.com, monica@unemat.br (2)Fundação de Apoio à Pesquisa Agropecuária de Mato Grosso, Centro de Pesquisa Dario Minoru Hiromoto, Avenida Antônio Teixeira dos Santos, o 1.559, Caixa Postal 79, Parque Universitário, CEP 78750-000 Rondonópolis, MT, Brasil. E-mail: luciavivan@fundacaomt.com.br ${ }^{(3)}$ Embrapa Recursos Genéticos e Biotecnologia, Parque Estação Biológica W5 Norte (Final), Caixa Postal 02372, CEP 70770-917 Brasília, DF, Brasil. E-mail: carolina.blassioli@embrapa.br, raul.laumann@embrapa.br, miguel.borges@embrapa.br
\end{abstract}

Resumo - O objetivo deste trabalho foi avaliar a eficiência das formulações septo de borracha e lure do feromônio sexual do percevejo marrom Euschistus heros e compará-la ao método do pano de batida, para o monitoramento dessa praga em lavoura de soja. Os tratamentos foram: feromônio em septo de borracha, feromônio em lure e amostragem com pano de batida. As amostragens foram realizadas semanalmente durante a fase reprodutiva da soja (dez semanas). Para estimar a densidade populacional de percevejos e compará-la à captura nas armadilhas de feromônio, foram efetuados quatro panos de batida por semana em todas as parcelas; além disso, foi determinado o número de percevejos capturados nas armadilhas por semana. Os danos provocados pelos percevejos nas sementes foram analisados pelo teste de tetrazólio. As formulações do feromônio foram eficientes na captura de E. heros, e a formulação em lure capturou mais percevejos. O controle precoce da população, indicado pelo nível de controle nas armadilhas com feromônio, resultou em sementes com maior qualidade do que as provenientes das parcelas monitoradas pelo pano de batida. Assim, as armadilhas com feromônio são mais eficientes que o pano de batida para o monitoramento das populações de percevejos durante a fase crítica do ataque deste inseto nas lavouras de soja.

Termos para indexação: armadilha de feromônio, pano de batida, percevejo marrom, qualidade das sementes.

\section{Monitoring of the brown stink bug Euschistus heros (Hemiptera: Pentatomidae) with sex pheromone in soybean fields}

\begin{abstract}
The objective of this work was to evaluate the efficiency of rubber septum and lure formulations of the brown stink bug Euschistus heros sex pheromone and to compare it with the shake cloth method for monitoring this pest in soybean fields. The treatments were: pheromone in rubber septum, pheromone in lure, and sampling with shake cloth. Samples were taken weekly during the soybean reproductive stage (ten weeks). To estimate bug population density and compare it with the capture in pheromone traps, four shake clothes per week were carried out in all plots; in addition, the number of bugs captured in traps was determined weekly. Damage caused by bugs in seeds was evaluated using the tetrazolium test. Pheromone formulations were effective in capturing E. heros, and the lure formulation captured more bugs. Early population control, indicated by the level of control in the pheromone traps, resulted in seeds with higher quality than those from plots monitored with shake cloth. Therefore, pheromone traps are more efficient than the shake cloth for monitoring stink bug populations during the critical phase of the bug attack in soybean fields.
\end{abstract}

Index terms: pheromone trap, shake cloth, brown stink bug, seed quality.

\section{Introdução}

O percevejo marrom Euschistus heros (F.) (Hemiptera: Pentatomidae) é uma praga-chave da cultura de soja (Glycine max L.) em várias regiões do Brasil, principalmente nas de clima quente (Godoy et al., 2010). Predominante nas lavouras de soja no Estado de Mato Grosso, esse inseto pode ocasionar danos irreversíveis à cultura, pois, para se alimentar, suga diretamente os grãos de soja, o que acarreta redução na produção e na qualidade das sementes (Depieri \& Panizzi, 2011; Silva et al., 2012). 
O controle das populações do inseto, muitas vezes, é realizado por meio de aplicações preventivas de inseticidas sintéticos (Bueno et al., 2013). O uso excessivo desses produtos promove a seleção de populações de percevejos resistentes, a redução dos inimigos naturais, a contaminação ambiental e riscos à saúde humana (Sosa-Gómez \& Silva, 2010; Bueno et al., 2011; Belo et al., 2012).

Para diminuir o uso de inseticidas, faz-se necessário estimar os níveis populacionais do inseto por meio de amostragens no campo, o que permite tomar decisões de manejo com base em informações confiáveis. Para o monitoramento de percevejos na soja, recomenda-se o método do pano de batida, no qual se considera como nível de controle a presença de dois percevejos adultos por metro linear, para a produção de grãos, e de um percevejo, para a produção de sementes (Bueno et al., 2013).

No entanto, o monitoramento com uso do pano de batida requer mão de obra qualificada, além de consumir muito tempo em razão da extensão das áreas em que a soja é cultivada, uma vez que é indicado realizar dez panos de batida a cada 100 ha (Corrêa-Ferreira et al., 2009). Por apresentar essas limitações, a técnica do pano de batida não é sempre adotada ou aplicada da maneira correta pelos produtores (Pires et al., 2006), o que conduz, em muitos casos, a aplicações ineficientes de inseticidas.

Uma alternativa prática e viável para $\mathrm{o}$ monitoramento das populações de E. heros seria a utilização de armadilhas com seu feromônio sexual. Esse monitoramento apresenta inúmeras vantagens, pois o feromônio é um composto natural com baixa agressividade ambiental, específico, não tóxico a humanos e que permite a rápida detecção do inseto no campo, o que fornece uma ferramenta precisa para a tomada de decisão (Borges et al., 1998, 2011; Millar, 2005; Moraes et al., 2008).

A eficiência do uso do feromônio sexual de $E$. heros em armadilhas já foi previamente comprovada. Borges et al. (1998) testaram a mistura racêmica (2,6,10-trimetiltridecanoato de metila) do feromônio sexual do percevejo $E$. heros e constataram que essa mistura também atrai outras espécies de pentatomídeos pragas, o que abre a possibilidade de utilizar uma única formulação de feromônio para monitorar o complexo de percevejos pragas da soja.
Borges et al. (2011) verificaram que as armadilhas com feromônio podem ser instaladas no perímetro da cultura, o que facilita o monitoramento do inseto no campo. Esses autores também evidenciaram que as armadilhas com feromônio foram mais eficientes que o método do pano de batida durante os estádios reprodutivos R1 (início da floração) a R5 (fase de enchimento dos grãos) da soja, período considerado crítico pelo potencial de danos dos insetos nas sementes. Contudo, ainda são necessárias informações mais detalhadas para avaliar a eficiência dessas armadilhas com feromônio em áreas mais extensas e em outras regiões sojícolas do Brasil, mais especificamente a eficiência da aplicação de métodos de controle, ao se tomar como referência o monitoramento pelas armadilhas com feromônio.

O objetivo deste trabalho foi avaliar a eficiência das formulações septo de borracha e lure do feromônio sexual do percevejo E. heros e compará-la ao método do pano de batida, para o monitoramento dessa praga em lavoura de soja.

\section{Material e Métodos}

O experimento foi realizado na Fazenda Aparecida da Serra, localizada no Município de Tangará da Serra, na região sudoeste do Estado de Mato Grosso

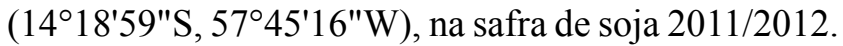

Foram avaliadas duas formulações sintéticas do feromônio sexual do percevejo E. heros, que foram preparadas com $1,0 \mathrm{mg}$ de uma mistura de estereoisômeros do 2,6,10 trimetiltridecanoato de metila. Uma formulação foi preparada em pastilhas celulósicas revestidas com plástico nanoporoso, formulação em lure (Fuji Flavor Co., Ltd., Tóquio, Japão), fornecidas pelo Laboratório de Semioquímicos da Embrapa Recursos Genéticos e Biotecnologia (Cenargen). Na outra formulação, o feromônio foi impregnado em septos de borracha de $11 \mathrm{~mm}$ de diâmetro (Isca Technologies, Riverside, CA, EUA).

Para a captura dos percevejos, foram utilizadas armadilhas de garrafa PET (politereftalato de etileno) incolor transparente de $2 \mathrm{~L}$, de acordo com o modelo desenvolvido originalmente por Borges et al. (1998). Essas armadilhas apresentam quatro orifícios no terço superior, cada uma com um funil de tela de arame galvanizado para a entrada dos insetos. Os septos com feromônio ficaram pendurados na parte interna da 
armadilha, com um arame preso à tampa da garrafa ao nível das aberturas, para permitir sua disseminação. Para evitar o escape dos percevejos, no interior da garrafa, abaixo dos orifícios de entrada, foi colocado um funil de PET, que possibilita que os insetos fiquem retidos no fundo da armadilha (Borges et al., 1998; Pires et al., 2006).

O experimento foi conduzido em área de soja de 130 ha, plantada com a cultivar TMG 132RR de ciclo semiprecoce, com espaçamento de $0,50 \mathrm{~m}$ entre plantas. Utilizou-se o delineamento experimental de blocos ao acaso, com três tratamentos e quatro repetições. Cada uma das 12 parcelas instaladas consistia de área de 200x200 m, com espaçamento entre parcelas de $100 \mathrm{~m}$. As parcelas foram divididas em três grupos nos quais o monitoramento dos percevejos foi realizado com um dos seguintes tratamentos: T1, duas armadilhas com feromônio em septo de borracha; T2, duas armadilhas com feromônio em lure; e T3, amostragem com quatro panos de batida por parcela.

As armadilhas foram instaladas na altura do dossel das plantas, no final do estádio vegetativo e no início da fase reprodutiva (V8-R1). A primeira avaliação ocorreu no estádio R2, uma semana após a instalação das armadilhas. No trigésimo dia de exposição no campo, as armadilhas de feromônios (lures e septos de borracha) foram substituídas, pois, de acordo com Borges et al. (2011), o tempo máximo para manutenção da formulação tipo lure no campo é de 49 dias. As armadilhas foram monitoradas semanalmente durante 71 dias (dez semanas), o que abrangeu todo o período reprodutivo da cultura da soja (R1 a R9).

Em cada parcela e data de monitoramento, registraram-se o número e a espécie dos percevejos. No caso de E. heros, os adultos foram quantificados ao se discriminar machos e fêmeas.

Para estimar a densidade populacional de percevejos e compará-la à captura nas armadilhas de feromônio, foram efetuados quatro panos de batida por semana em todas as parcelas, durante todo o período de avaliação.

Para comparar a eficiência dos monitoramentos pelas armadilhas com feromônio e pelo pano de batida no manejo de populações de E. heros, os dados de captura semanal nas armadilhas e no pano de batida (nas parcelas sem armadilhas) foram utilizados como parâmetro para a tomada da decisão de controle populacional, tendo-se estabelecido os seguintes níveis de controle: parcelas monitoradas por meio de armadilhas com feromônio de 1,7 percevejo por armadilhas por semana (Borges et al., 2011); e parcelas monitoradas pelo pano de batida, com dois percevejos adultos por metro linear (Bueno et al., 2013).

Quando a população de percevejos atingiu o nível de controle nas parcelas de cada tratamento (média), foi feita a aplicação do inseticida acefato (organofosforado), aplicado na dosagem de $500 \mathrm{~g}$ ha $^{-1}$ com pulverizador autopropelido. Além disso, foi realizada, por decisão do produtor, uma aplicação de fungicida sistêmico com inseticida organofosforado em toda a área, em 29/1/2012, quando a soja estava no estádio R5.2.

Para verificar se o estado fisiológico (reprodutivo) das fêmeas tem relação com a captura dos insetos nas armadilhas, todas as fêmeas de E. heros capturadas nos tratamentos, em cada semana de monitoramento, foram dissecadas em microscópio estereoscópico, para quantificar o número de ovos formados em seus óvarios.

Para avaliar a eficiência de captura das formulações sintéticas do feromônio com uso dos liberadores (lure e septos de borracha), os números médios de percevejos $E$. heros (fêmeas+machos) capturados durante $\mathrm{o}$ experimento pelas armadilhas foram comparados por meio de modelos lineares generalizados mistos (MLGM) e análise de deviança. Foram considerados, como fatores fixos, os tratamentos e as datas de amostragem e, como fatores aleatórios, as medidas repetidas nas parcelas e nos blocos. O modelo de análise considerou a distribuição de erros de Poisson e o $\log$ como função de ligação.

Para estimar a relação de captura de percevejos adultos de E. heros (fêmeas+machos) entre o método do pano de batida e as armadilhas com feromônio, o número médio de insetos capturados nas armadilhas por semana e o número médio de insetos nos panos de batida por semana foram transformados em raiz quadrada de $\mathrm{x}$, para normalização, sendo analisados por meio de análise de regressão simples. Foram consideradas como variável resposta o número médio de E. heros retidos no pano de batida, em todas as parcelas experimentais ou as parcelas monitoradas pelas armadilhas de feromônios, e, como variável explicativa, o número médio de percevejos capturados nas armadilhas com feromônio.

Foi estimada a relação de captura de percevejos adultos de E. heros (fêmeas+machos) nas armadilhas 
com feromônio, bem como o número de ovos nos ovários das fêmeas de E. heros durante as dez semanas de avaliação do experimento; os dados foram transformados em raiz quadrada de $\mathrm{x}$, para normalização, e analisados por análise de regressão simples.

Para a avaliação da eficiência dos diferentes métodos de monitoramento de E. heros, foram comparadas as curvas de flutuação populacional nas parcelas de cada tratamento. Também foram considerados o número de aplicações de inseticidas e o impacto dos insetos na produção, por meio da quantificação do dano provocado pelos percevejos nas sementes de soja.

O impacto dos percevejos na produção de sementes foi determinado pela coleta das vagens de cinco plantas de soja, em cinco pontos aleatórios de cada parcela. Posteriormente, essas vagens foram levadas para o laboratório e trilhadas manualmente. As sementes de cada planta e parcela foram misturadas, tendo-se armazenado 1.000 sementes a $18^{\circ} \mathrm{C}$. Previamente ao armazenamento, os lotes de 1.000 sementes foram pesados em balança de precisão Ohaus Adventurer, modelo ARD 110 (Ohaus, Barueri, SP). Posteriormente, para avaliar o efeito dos percevejos na qualidade das sementes, quatro grupos de 50 sementes foram separados para condução do teste de tetrazólio, seguindo as metodologias descritas em França Neto et al. (1998). Após a condução do teste, as sementes foram classificadas individualmente nos grupos propostos por França Neto et al. (1998): 1, vigor muito alto; 2, vigor alto; 3 , vigor médio; 4 , vigor baixo; 5 , vigor muito baixo; 6 e 7, sementes não viáveis; e 8 , sementes mortas.

O total de sementes de cada amostra dos grupos 1 a 5 foi utilizado para calcular a percentagem de sementes viáveis, e o total dos grupos 1 a 3, para calcular o vigor de acordo com as categorias sugeridas por França Neto et al. (1998): $\geq 85 \%$, vigor muito alto; 84 a $75 \%$, vigor alto; 74 a $60 \%$, vigor médio; 59 a $50 \%$, vigor baixo; e $\leq 49 \%$, vigor muito baixo.

Os dados de percentagens de sementes viáveis e de percentagens de sementes nos grupos 1 a 3 (vigor) para cada parcela e em cada um dos métodos de monitoramento (armadilhas com feromônio e pano de batida) foram transformados em arco seno da raiz quadrada de $(x+0,5) / 100$, para garantir a normalidade das variâncias, e foram submetidos à análise de variância e ao teste de comparação de médias de Tukey, a $5 \%$ de probabilidade.

Todas as análises estatísticas foram realizadas com uso do programa $\mathrm{R}$, versão 2.13.0 (R Development Core Team, 2013), com nível de significância de 5\%.

\section{Resultados e Discussão}

As armadilhas com feromônio sexual capturaram preferencialmente fêmeas dos percevejos, o que representa 77 e $82 \%$ dos insetos retidos nas armadilhas com a formulação em septos de borracha e lure, respectivamente. Ao se considerar a captura de insetos nas armadilhas durante todo o período experimental, foram constatadas diferenças significativas entre as formulações de feromônios pela análise MLGM $(\mathrm{z}=-2,81 ; \mathrm{p}=0,005)$ e entre as semanas de amostragem relacionadas aos estágios fenológicos da cultura ( $\mathrm{z}=-6,241 ; \mathrm{p}<0,001)$; entretanto, não houve interação significativa entre esses fatores $(\mathrm{z}=0,820 ; \mathrm{p}=0,41)$. As armadilhas com o feromônio em lure capturaram, em média, um número maior de percevejos $E$. heros, quando comparado ao feromônio impregnado em septo de borracha.

A maior captura nas armadilhas com o feromônio em lure do que nas armadilhas com o feromônio em septo de borracha pode estar relacionada às variações na taxa de liberação do feromônio nos diferentes materiais empregados nos liberadores. Tiboni et al. (2008), ao comparar a liberação de feromônio em septos de borracha com vidro poroso do tipo Vycor (PVG), observaram que o PVG apresentou liberação mais estável, enquanto o septo de borracha apresentou grandes flutuações de liberação do feromônio. Além disso, Borges et al. (2011), ao avaliar a taxa de liberação de lures (Fuji Flavor Co. Ltd., Tóquio, Japão) contendo $1,0 \mathrm{mg}$ do feromônio do percevejo $E$. heros, relataram taxa de liberação com baixa variabilidade ao longo de 63 dias.

As armadilhas com feromônio capturaram preferencialmente o percevejo E. heros $(98,7 \%$ dos insetos capturados), mas, também, foi registrada a captura do percevejo Dichelops furcatus (F.) (1,3\% dos insetos capturados). As armadilhas com feromônio ainda capturaram 24 indivíduos do gênero Apiomerus sp. família Reduviidae, considerado predador generalista de insetos (Marques et al., 2006). 
A captura de espécies não alvo em armadilhas com feromônio sexual de percevejos (atração cruzada) é um fato recorrente na literatura (Endo et al., 2006; Pires et al., 2006; Aldrich et al., 2007; Borges et al., 2011; Laumann et al., 2011).

Para explicar esse padrão de atração cruzada a feromônios observado em fitófagos Pentatomidae, têm sido propostas duas hipóteses alternativas. Uma sugere que a atração cruzada a feromônios de outras espécies pode ser indicativo do uso dos feromônios como cairomônios durante a procura por plantas hospedeiras (Endo et al., 2006). A outra hipótese relaciona-se à agregação de indivíduos em grupos heteroespecíficos e à obtenção de maior proteção contra predadores (Aldrich et al., 2007). A captura do percevejo predador Apiomerus sp. (Reduviidae) é um fato novo e não relatado previamente na literatura, e sugere que esse predador generalista poderia utilizar feromônios de presas potenciais como cairomônios durante o forrageamento. A relação entre a densidade de percevejos capturados nas armadilhas com feromônio e a densidade de percevejos estimada pelo método do pano de batida, estimada por regressão linear, foi significativa em ambos os tratamentos. A relação entre densidade de insetos (y) e número de insetos por armadilha (x) para feromônios em septos de borracha e lure foram, respectivamente: $\mathrm{y}=1,39-0,95 \mathrm{x}, \mathrm{R}^{2}=0,33$, $\mathrm{F}_{1,8}=5.53, \mathrm{p}=0,046$; e $\mathrm{y}=1,2561-0,6801 \mathrm{x}, \mathrm{R}^{2}=0,54$, $\mathrm{F}_{1,8}=11.66, \mathrm{p}=0,009$.

Os coeficientes de determinação estimados pelas análises de regressão foram baixos, o que pode estar relacionado à diminuição da captura de percevejos pelas armadilhas com feromônio no período final do ciclo da cultura (Figura 1). Resultados similares foram relatados previamente para outras espécies de Pentatomidae, como E. conpersus Uhler (Cullen \& Zalom, 2005), e para E. heros (Borges et al., 2011). Assim, a diminuição nas capturas de percevejos nas armadilhas com feromônio no período final dos ciclos culturais parece ser um padrão geral para os percevejos e pode estar associada a duas situações: à composição da população, que, nos estágios finais do ciclo da cultura, é dominada por ninfas; e à diminuição da resposta ao feromônio pelas fêmeas, originada por

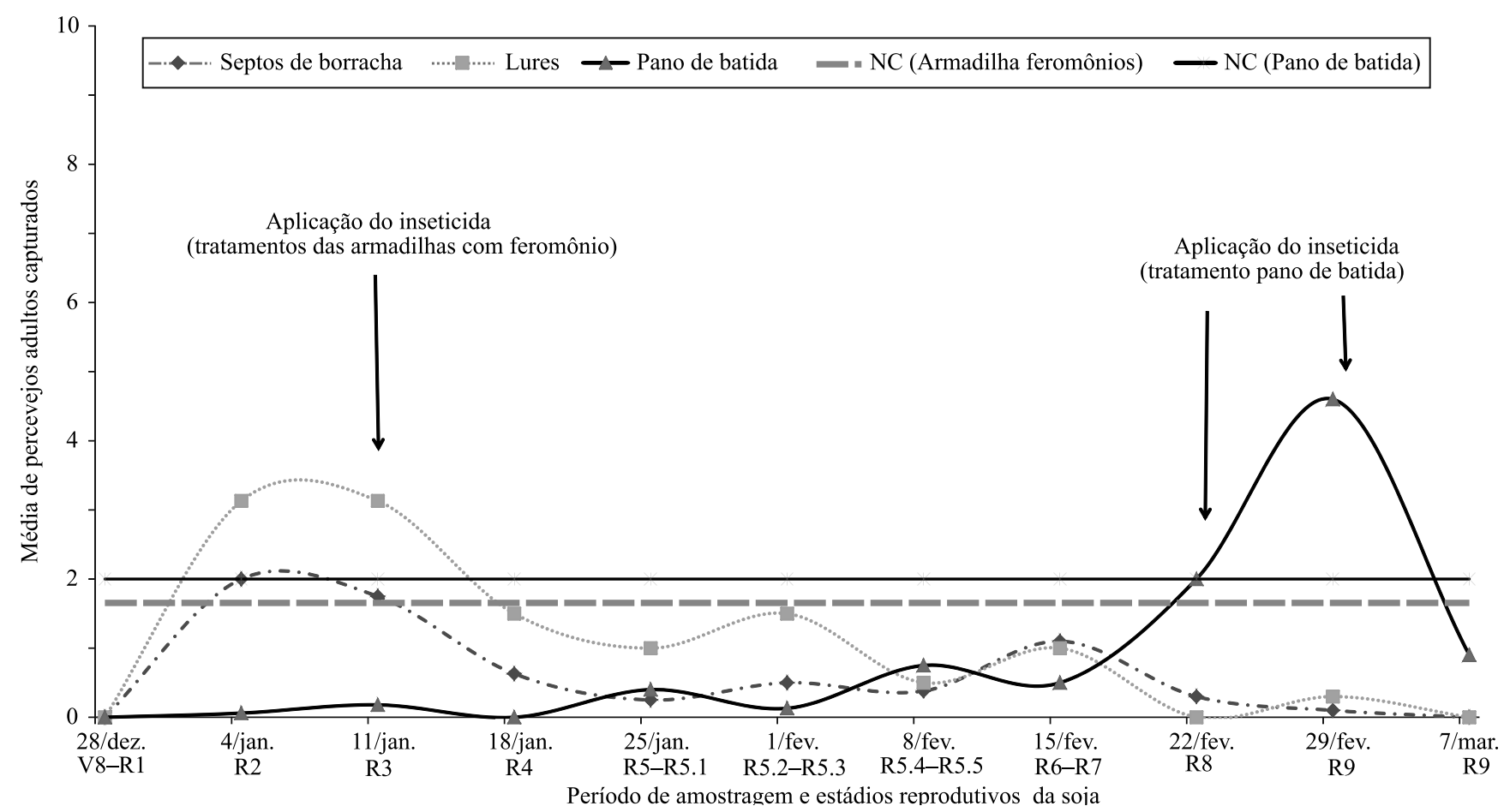

Figura 1. Média do número de percevejos adultos de Euschistus heros capturados pelas armadilhas com feromônios impregnados em septos de borracha e lures e pelo método do pano de batida, e aplicações de inseticidas durante o experimento. NC, nível de controle. As setas indicam o momento da aplicação de inseticida acefato (organofosforado), aplicado na dosagem de $500 \mathrm{~g} \mathrm{ha}^{-1}$ com pulverizador autopropelido. 
mudança na condição fisiológica da população, em que as fêmeas estariam imaturas sexualmente e não responderiam ao feromônio (Borges et al., 2011).

Ambas as hipóteses são sustentadas pelos dados coletados na área experimental, já que a proporção de ninfas na população mostra claro incremento nos estágios finais do ciclo (Figura 2). Além disso, a dissecação das fêmeas capturadas ao longo do período experimental para a contagem de ovos presentes no sistema reprodutor indica que, nos estágios finais da cultura, uma alta percentagem das fêmeas da população não estava ativa reprodutivamente (Figura 3 ).

Nos estágios R1 a R4 do ciclo da soja, as armadilhas mostraram maior eficiência que o pano de batida para detectar os insetos, mesmo quando a população apresentava baixa densidade(Figura 1). Cullen \& Zalom (2006) e Borges et al. (2011) obtiveram resultados semelhantes, o que sugere que as armadilhas com feromônios são altamente eficientes para identificar a migração e a colonização de percevejos nas culturas.

Em relação ao controle da população de percevejos, no período R1 a R5.5, somente o monitoramento pelas armadilhas com feromônio indicou a necessidade de controle populacional. Nas parcelas monitoradas por esses tratamentos, o nível de controle foi alcançado no período de floração plena (R2) (Figura 1); no entanto, a aplicação do inseticida ocorreu após a segunda avaliação, quando a cultura iniciou a formação das vagens (R3) (Figura 1). Já no tratamento com monitoramento pelo pano de batida, foram realizadas duas aplicações de inseticidas nos estádios fenológicos R8 e R9. Dessa forma, a aplicação inicial de inseticidas, resultante do monitoramento pelas armadilhas com feromônio, contribuiu para controlar eficientemente o crescimento populacional, bem como para reduzir uma aplicação de inseticidas em relação às parcelas monitoradas por pano de batida e para aumentar a viabilidade e o vigor das sementes.

A viabilidade das sementes dos grupos 1 a 5 da escala sugerida por França Neto et al. (1998) para o teste de tetrazólio, nas parcelas monitoradas pelas armadilhas de feromônio em lure e septo de borracha, foram maiores que a viabilidade das sementes das parcelas monitoradas pelo pano de batida (Figura 4 A).

As sementes de soja das parcelas onde a população de percevejos foi monitorada pelas armadilhas com feromônio também apresentaram maiores percentagens nos grupos de classificação de vigor (soma dos grupos 1 a 3) (Figura 4 B). De acordo com a classificação do teste de tetrazólio (França Neto et al., 1998), as sementes oriundas das parcelas monitoradas por ambas as formulações de feromônios (lure e septo de borracha) se enquadram no grupo de sementes com vigor muito alto ( $>85 \%$ das sementes no grupos 1 a 3 ), e as sementes das parcelas monitoradas pelo pano de batida se enquadraram no de sementes de vigor médio (entre 74 e 60\%).

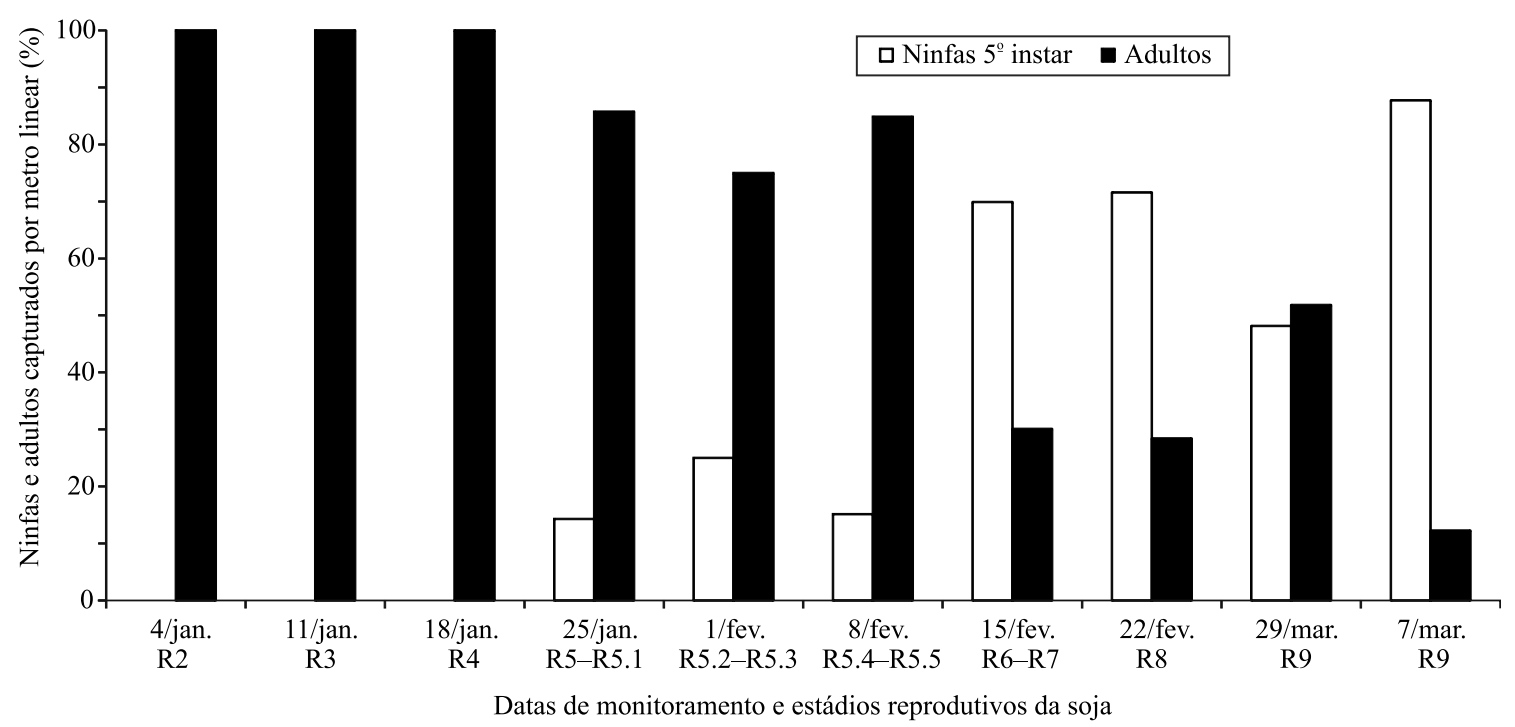

Figura 2. Percentagens de ninfas e adultos de Euchistus heros por metro linear, durante o período de janeiro a março de 2012, capturados por meio do pano de batida $(n=48)$. 


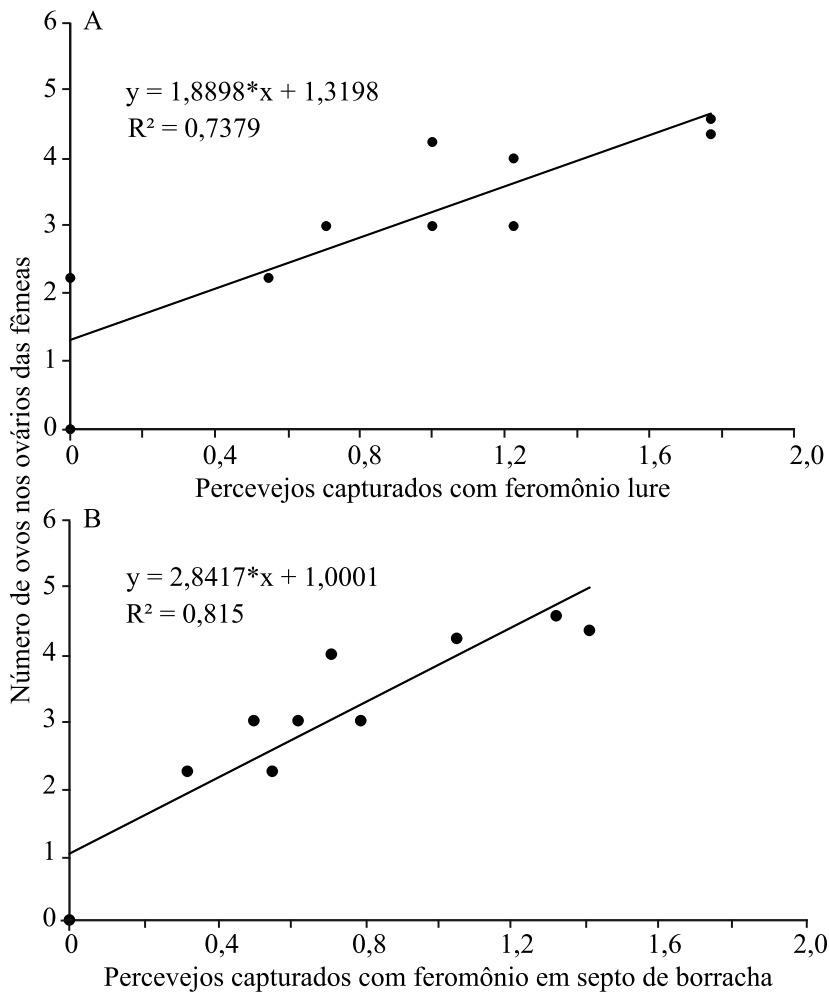

Figura 3. Relação entre o número de ovos formados nos ovários das fêmeas com a captura de percevejos Euchistus heros pelas armadilhas com feromônio impregnado em lure (A); e em septo de borracha (B). *Significativo a 5\% de probabilidade.

Quanto ao peso das sementes, não foram constatadas diferenças significativas entre os tratamentos. Isso pode estar relacionado aos níveis populacionais de E. heros durante a fase crítica da soja, que não ultrapassaram dois percevejos adultos por metro linear. Segundo Gazzoni (1998), o nível populacional de até quatro percevejos afeta apenas a qualidade dos grãos, mas não afeta o peso e, consequentemente, a produtividade.

A detecção precoce da população de percevejos na cultura de soja, quando as populações são monitoradas por armadilhas com feromônio, contribui para um controle eficiente da população de percevejos, com aumento da qualidade das sementes e redução de uma aplicação de inseticidas.

\section{Conclusões}

1. O feromônio sexual sintético impregnado em lure captura maior número de adultos de percevejo marrom Euschistus heros do que o feromônio em septo de borracha.
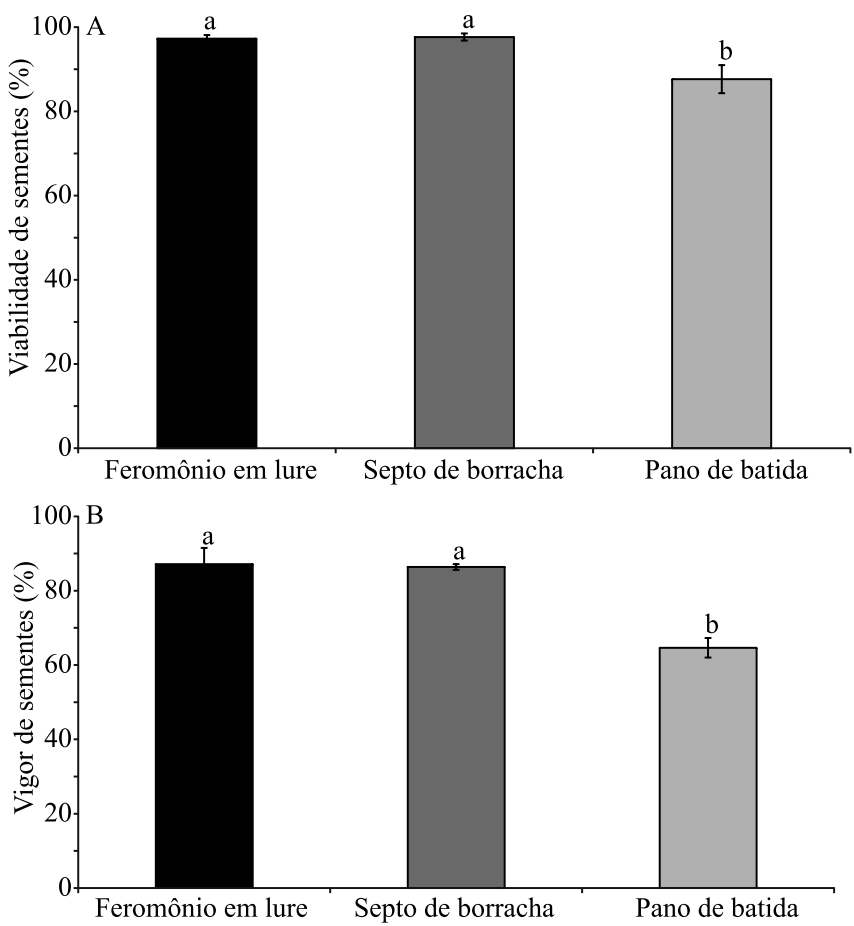

Figura 4. Médias \pm desvio-padrão da viabilidade (A) e vigor (B) das sementes de soja em parcelas monitoradas por diferentes métodos: feromônio em lure, feromônio em septo de borracha e pano de batida. A classificação de viabilidade e vigor foi estabelecida de acordo com França Neto et al. (1998). Médias seguidas de letras iguais não diferem pelo teste de Tukey, a 5\% de probabilidade.

2. Durante o período crítico do ataque dos percevejos à soja, dos estágios R1 a R4, as armadilhas com feromônio são mais eficientes para captura e monitoramento desses insetos no campo do que a técnica do pano de batida.

3. A aplicação do inseticida no início da infestação da cultura, como resultado do monitoramento populacional por armadilhas iscadas com o feromônio sexual, resulta em um controle mais eficiente da população de E. heros, com redução dos danos nas sementes.

\section{Agradecimentos}

Ao Dr. Carlos Campaner do Museu de Zoologia da Universidade de São Paulo (USP), pela identificação dos Reduviidae; à Coordenação de Aperfeiçoamento de Pessoal de Nível Superior (Capes), pela concessão de bolsa; ao Conselho Nacional de Desenvolvimento Científico e Tecnológico (CNPq), pelo apoio financeiro; ao grupo Franciosi, pela disponibilidade da área de soja 
no Município de Tangará da Serra, MT; à toda equipe do laboratório de Entomologia do Centro de Pesquisas, Estudos e Desenvolvimento Agroambientais (CPEDA) da Universidade do Estado de Mato Grosso (Unemat), pela colaboração na coleta de dados no campo; e à Embrapa e à Isca Tecnologias, pelo fornecimento das formulações de feromônios.

\section{Referências}

ALDRICH, J.R.; KHRIMIAN, A.; CAMP, M.J. Methyl 2,4,6-decatrienoates attract stink bugs (Hemiptera: Heteroptera: Pentatomidae) and tachinid parasitoids. Journal of Chemical Ecology, v.33, p.801-815, 2007. DOI: 10.1007/ s10886-007-9270-9.

BELO, M.S. da S.P.; PIGNATI, W.; DORES, E.F.G. de C.; MOREIRA, J.C.; PERES, F. Uso de agrotóxicos na produção de soja do Estado do Mato Grosso: um estudo preliminar de riscos ocupacionais e ambientais. Revista Brasileira de Saúde Ocupacional, v.37, p.78-88, 2012. DOI: 10.1590/ S0303-76572012000100011.

BORGES, M.; MORAES, M.C.B.; PEIXOTO, M.F.; PIRES, C.S.S.; SUJI, E.R.; LAUMANN, R.A. Monitoring the Neotropical brown stink bug Euschistus heros (F.) (Hemiptera: Pentatomidae) with pheromone-baited traps in soybean fields. Journal of Applied Entomology, v.135, p.68-80, 2011. DOI: 10.1111/j.1439-0418.20 10.01507.x.

BORGES, M.; SCHIMIDT, F.G.V.; SUJII, E.R.; MEDEIROS, M.A.; MORI, K.; ZARBIN, P.H.G.; FERREIRA, T.B. Field responses of stink bugs to the natural and synthetic pheromone of the Neotropical brown stink bug, Euschistus heros (Heteroptera: Pentatomidae). Physiological Entomology, v.23, p.202-207, 1998. DOI: 10.1046/j.1365-3032.1998.233086.x.

BUENO, A. de F.; BATISTELA, M.J.; BUENO, R.C.O. de F.; FRANÇA-NETO, J.B.; NISHIKAWA, M.A.N.; LIBÉRIO FILHO, A. Effects of integrated pest management, biological control and prophylactic use of insecticides on the management and sustainability of soybean. Crop Protection, v.30, p.937-945, 2011. DOI: 10.1016/j.cropro.2011.02.021.

BUENO, A.F.; PAULA-MORAES, S.V.; GAZZONI, D.L.; POMARI, A.F. Economic thresholds in soybean-integrated pest management: old concepts, current adoption, and adequacy. Neotropical Entomology, v.42, p.439-447, 2013. DOI: 10.1007/ s13744-013-0167-8.

CORRÊA-FERREIRA, B.S.; KRZYZANOWSKI, F.C.; MINAMI, C.A. Percevejos e a qualidade da semente de soja - série sementes. Londrina: Embrapa Soja, 2009. 15p. (Embrapa Soja. Circular técnica, 67).

CULLEN, E.M.; ZALOM, F.G. Euschistus conspersus female morphology and attraction to methyl (2E,4Z)-decadienoate pheromone-baited traps in processing tomatoes. Entomologia Experimentalis et Applicata, v.119, p.163-173, 2006. DOI: 10.1111/j.1570-7458.2006.00407.x.
CULLEN, E.M.; ZALOM, F.G. Relationship between Euschistus conspersus (Hem., Pentatomidae) pheromone trap catch and canopy samples in processing tomatoes. Journal of Applied Entomology, v.129, p.505-514, 2005. DOI: 10.1111/j.1439-041 8.2005.01013.x.

DEPIERI, R.; PANIZZI, A.R. Duration of feeding and superficial and in-depth damage to soybean seed by selected species of stink bugs (Heteroptera: Pentatomidae). Neotropical Entomology, v.40, p.197-203, 2011. DOI: 10.1590/S1519-566X2011000200007.

ENDO, N.; WADA, T.; NISHIBA, Y.; SASAKI, R. Interspecific pheromone cross-attraction among soybean bugs (Heteroptera): does Piezodorus hybneri (Pentatomidae) utilize the pheromone of Riptortus clavatus (Alydidae) as a kairomone? Journal of Chemical Ecology, v.32, p.1606-1612, 2006. DOI: 10.1007/ s10886-006-9093-0.

FRANÇA NETO, J.B.; KRZYZANOWSKI, F.C.; COSTA, N.P. da. O teste de tetrazólio em sementes de soja. Londrina: Embrapa-CNPSO, 1998. 72p. (Embrapa-CNPSO. Documentos, 116).

GAZZONI, D.L. Efeito de populações de percevejos na produtividade, qualidade da semente e características agronômicas da soja. Pesquisa Agropecuária Brasileira, v.33, p.1229-1237, 1998.

GODOY, K.B.; ÁVILA, C.J.; DUARTE, M.M.; ARCE, C.C.M. Parasitismo e sítios de diapausa de adultos do percevejo marrom, Euschistus heros na região da Grande Dourados, MS. Ciência Rural, v.40, p.1199-1202, 2010. DOI: 10.1590/ S0103-84782010005000074.

LAUMANN, R.A.; MORAES, M.C.B.; KHRIMIAN, A.; BORGES, M. Field capture of Thyanta perditor with pheromone baited traps. Pesquisa Agropecuária Brasileira, v.46, p.113-119, 2011. DOI: 10.1590/S0100-204X2011000200001.

MARQUES, O.M.; GIL-SANTANA, H.R.; COUTINHO, M.L.; SILVA JÚNIOR, D.D. da. Percevejos predadores (Hemiptera, Reduviidae, Harpactorinae) em fumo (Nicotiana tabacum L.) no município de Cruz das Almas, Bahia. Revista Brasileira de Zoociências, v.8, p.55-59, 2006.

MILlAR, J.G. Pheromones of true bugs. Topics in Current Chemistry, v.240, p.37-84, 2005. DOI: 10.1007/b98315.

MORAES, M.C.B.; PAREJA, M.; LAUMANN, R.A. BORGES, M. The chemical volatiles (Semiochemicals) produced by neotropical stink bugs (Hemiptera: Pentatomidae). Neotropical Entomology, v.37, p.489-405, 2008. DOI: 10.1590/ S1519-566X2008000500001.

PIRES, C.S.S.; SUJII, E.R.; SCHMIDT, F.G.V.; ZARBIN, P.H.G.; ALMEIDA, J.R.M. de; BORGES, M. Potencial de uso de armadilhas iscadas com o feromônio sexual do percevejo marrom, Euschistus heros (Heteroptera: Pentatomidae), para o monitoramento populacional de percevejos praga da soja. Manejo Integrado de Plagas y Agroecología, v.77, p.70-77, 2006.

R DEVELOPMENT CORE TEAM. R: a language and environment for statistical computing. Vienna: R Foundation for Statistical Computing, 2013. 
SILVA, F.A.C.; SILVA, J.J. da; DEPIERI, R.A.; PANIZZI, A.R. Feeding activity, salivary amylase activity, and superficial damage to soybean seed by adult Edessa meditabunda (F.) and Euschistus heros (F.) (Hemiptera: Pentatomidae). Neotropical Entomology, v.41, p.386-390, 2012. DOI: 10.1007/s13744-012-0061-9.

SOSA-GÓMEZ, D.R.; SILVA, J.J. da. Neotropical brown stink bug (Euschistus heros) resistance to methamidophos in Paraná,
Brazil. Pesquisa Agropecuária Brasileira, v.45, p.767-769, 2010. DOI: $10.1590 /$ S0100-204X2010000700019.

TIBONI, A.; CORACINI, M.D.A.; LIMA, E.R.; ZARBIN, P.H.G.; ZARBIN, A.J.G. Evaluation of porous silica glasses as insect pheromone dispensers. Journal of the Brazilian Chemical Society, v.19, p.1634-1640, 2008. DOI: 10.1590/S010350532008000800026 .

Recebido em 17 de março de 2014 e aprovado em 25 de setembro de 2014 